\title{
PREDICTING EXACERBATIONS IN COPD PATIENTS USING MULTIDIMENSIONAL ASSESSMENT SYSTEMS, BASED ON GOLD STAGING CRITERIA
}

\author{
Rajathilakam Nadarajan Kumari ${ }^{1}$, Poriyanganattu Thankappan Anandan²
}

${ }^{1}$ Senior Resident, Department of Pulmonary Medicine, Government Medical College, Parippally, Kollam, Kerala. ${ }^{2}$ Assistant Professor, Department of Pulmonary Medicine, Government Medical College, Kozhikode, Kerala.

\section{ABSTRACT}

\section{BACKGROUND}

Exacerbations of COPD are events in the life of people with COPD leading to fall in pulmonary functions and premature death. Prediction of such events assumes significance, since prompt identification and treatment can modify outcomes in such patients. Various assessment tools are available that can predict outcomes in COPD, but there are only few studies available from India.

Aim- Aim of this study was to assess COPD exacerbation in various severity groups as per GOLD 2013 criteria and to find out which of the three multidimensional assessment systems, BODE index, DOSE index or ADO index is better in predicting exacerbations.

\section{MATERIALS AND METHODS}

This is a prospective cohort study carried out in a tertiary care teaching hospital in North Kerala from January 2014 to June 2015. Study population includes COPD patients attending the OPD or inpatients stabilised after admission to the hospital, and they were followed up monthly for 1 year. Data on the outcome measures and associated factors were collected in a stable state and predictions of exacerbation by the three assessment systems were compared. Statistical analysis was done using SPSS software version 18.

\section{RESULTS}

Out of 300 patients included in the study, 12 (4\%) lost followup and 24 (8\%) died during the study period. Of the total patients, 62 (20.7\%) were belonging to the group B and 238 (79.3\%) in the group D of 2013 GOLD staging criteria. The mean annual exacerbation rate was 2.8 events per patients per year. Rate of exacerbation correlated with lower predicted forced expiratory volume in 1 second (FEV1), lesser 6 MWD, higher mMRC dyspnoea score, GOLD stage D, higher DOSE index, higher BODE index and higher ADO index. For prediction of exacerbations, the area under curve was larger for BODE index than for DOSE \& ADO index, all these findings being statistically significant.

\section{CONCLUSION}

Multidimensional assessment tools, DOSE, ADO and BODE index can be used to predict exacerbations in COPD in Indian patients. BODE index was a better predictor of COPD exacerbation, compared to DOSE and ADO index.

\section{KEYWORDS}

COPD Exacerbation, Multidimensional Assessment System, DOSE Index, BODE Index, ADO Index.

HOW TO CITE THIS ARTICLE: Kumari RN, Anandan PT. Predicting exacerbations in COPD patients using multidimensional assessment systems, based on GOLD staging criteria. J. Evolution Med. Dent. Sci. 2017;6(42):3313-3316, D0I: 10.14260/Jemds/2017/717

\section{BACKGROUND}

In spite of being one of the worst affected countries with nearly 15 million elderly population affected with COPD, credible data on the extent and magnitude of the disease is still lacking in India. Due to the non-availability of nationwide data, the exact trend of the disease is not known. However, available literature point towards an increasing trend in the morbidity and mortality due to COPD. Exacerbations of COPD adversely affect the patients with COPD in several ways. It causes decreased quality of life, predisposes to rapid fall in lung functions, frequent hospitalisations and ultimately

Financial or Other, Competing Interest: None.

Submission 19-04-2017, Peer Review 13-05-2017,

Acceptance 19-05-2017, Published 25-05-2017.

Corresponding Author:

Rajathilakam Nadarajan Kumari,

Senior Resident,

Government Medical College,

Parippally, Kollam, Kerala.

E-mail: rajathilakamnk@gmail.com

DOI: $10.14260 /$ jemds $/ 2017 / 717$ premature death. Moreover economic cost of these events is substantial.[1] Thus, it becomes important to have simple and reliable tools that can predict COPD exacerbations.

Several factors have been considered as predictors of COPD exacerbations in the past. Literature shows decreased forced expiratory volume in 1 second (FEV1), past exacerbations, hospitalisation, old age and long-term oxygen therapy being a few among them. BODE index, introduced by Celli BR et al was the first multidimensional system to attempt this.[2] It uses body mass index, airflow obstruction, dyspnoea and exercise capacity to predict risk for exacerbation. This was found to be better than FEV1 alone, when used for prediction. Another system which came later was ADO index, based on age, dyspnoea and airflow obstruction, to be followed by DOSE index, using dyspnoea, airflow obstruction, smoking status and exacerbations in the past year.[3,4] Determining whether these multidimensional systems were able to predict COPD exacerbations and which among them performs well in predicting exacerbations was the purpose of this study. 


\section{Aim}

The purpose of this study is to assess exacerbation of COPD in multiple severity groups as per GOLD 2013 criteria and to find out which of the three multidimensional assessment systems BODE, DOSE or ADO index is better in predicting exacerbations.

\section{MATERIALS AND METHODS}

300 patients with a diagnosis of COPD, meeting GOLD 2013 guidelines, were enrolled from January 2014 to June 2014 after excluding ischaemic heart disease and other major respiratory diseases like active tuberculosis, bronchiectasis, interstitial lung diseases, malignancy, etc. This was a prospective cohort study conducted in a tertiary care teaching hospital (Institute of chest diseases, Government Medical College) in Kozhikode, Kerala, India, among COPD patients attending the OPD or inpatients immediately prior to discharge from the hospital. Data on the outcome measures and associated factors were collected in a stable state and they were followed up for 1 year. The study was approved by the ethics committee of the institution, and patients were enrolled only after receiving appropriate written informed consent. Relevant history was taken for the purpose of severity classification as per GOLD 2013 staging criteria. They were assessed for comorbidities. Oxygenation status was assessed by finger pulse oximetry. A 6-minute walk test was performed for all patients based on ATS 2002 criteria. In patients who were not able to perform a 6-minute walk test, distance covered will be recorded as zero. Baseline FEV1 was measured in all cases. Pulmonary functional parameters were measured according to the American Thoracic Society (ATS) guideline.[5] Sputum microscopy was done, if exacerbation was suspected. Chest radiography was taken to rule out complications like pneumonia, pneumothorax, nodule or mass. ECG taken to detect pulmonary hypertension, coronary artery disease, left or right ventricular hypertrophy and arrhythmias. Routine blood investigations were done in all patients and further investigations were done according to the relevance in the case. Subjects were followed up every month for 1 year. Occurrences of exacerbations were recorded monthly during the 1 year study period. The mMRC stage, $\mathrm{SpO}_{2}$ were recorded monthly and 6 MWD and FEV1 at the end of 1 year. Patients who missed followup were telephoned and requested to review. In debilitated patients, symptoms were analysed via telephone conversation with the patient or the caregiver.

The three multidimensional assessment systems, BODE, $\mathrm{ADO}$, and DOSE indices were calculated from the data obtained. $[2,3,4,5]$ The rates of previous exacerbations for the DOSE index were calculated from the exacerbation frequencies of the previous year of the study period from medical records and history.

\section{Statistical Analysis}

The study population was divided in two groups according to the number of exacerbations, $0-1$ per year and 2 or more per year. Pearson's Chi-square test was used to compare discrete variables among these groups and GOLD stages. Different multidimensional system indices, BODE, DOSE and ADO were compared using Receiver operator characteristic curve. Area under the curve was calculated with values ranging 0 to 1 and more than 0.8 showing good discrimination. Statistical analysis was done using SPSS version $18 .^{6}$

\section{RESULTS}

Total 300 patients with COPD were enrolled from January 2014, among these, 12 patients lost followup during the study period and were excluded. Remaining 288 patients were followed up for 1 year. 24 patients died during followup and data of the remaining 264 were analysed.

Males constituted majority of the patients (95.7\%), mean age of the population was 65.83 (SD 7.57). Comorbidities detected were Diabetes mellitus.(7) Systemic Hypertension(8) and Pulmonary hypertension.(9) Smoking history revealed $86 \%$ were ex-smokers, whereas $5.3 \%$ were continuing smoking and the rest non-smokers.

Reviewing the exacerbation history showed majority had more than 2 exacerbations (Table - 1). The overall exacerbation for the past 1 year was 2.42 . $61 \%$ of the study population were belonging to the mMRC grade 3 ; nearly $20 \%$ each were with grade 2 and 4. GOLD staging of the population showed only two stages, $79.3 \%$ in the D and $20.7 \%$ in the B (Chart 1). $35.5 \%$ of B and $85.3 \%$ of stage D had more than 2 exacerbations (Table-4). Estimates of the risk of exacerbations in DOSE, ADO and BODE index of the population were 2.316 (95\% CI 1.711- 3.134), 1.774 (95\% CI 1.381-2.280), 2.803 (95\% CI 1.855-4.235) respectively (Table-5). All these values were statistically significant with a p value $<0.001$

\begin{tabular}{|c|c|c|}
\hline Exacerbation in the Last 1 Year & Number & Percentage \\
\hline$<2$ & 82 & $27.3 \%$ \\
\hline$>2$ & 218 & $82.7 \%$ \\
\hline Total & 300 & $100 \%$ \\
\hline \multicolumn{3}{|l|}{$\begin{array}{l}\text { Exacerbation during the Study } \\
\text { Period of } 1 \text { Year }\end{array}$} \\
\hline$<2$ & 39 & $13 \%$ \\
\hline$>2$ & 225 & $75 \%$ \\
\hline Total & 264 & $88 \%$ \\
\hline \multicolumn{3}{|c|}{ Table 1. Exacerbations in the Study Population } \\
\hline
\end{tabular}

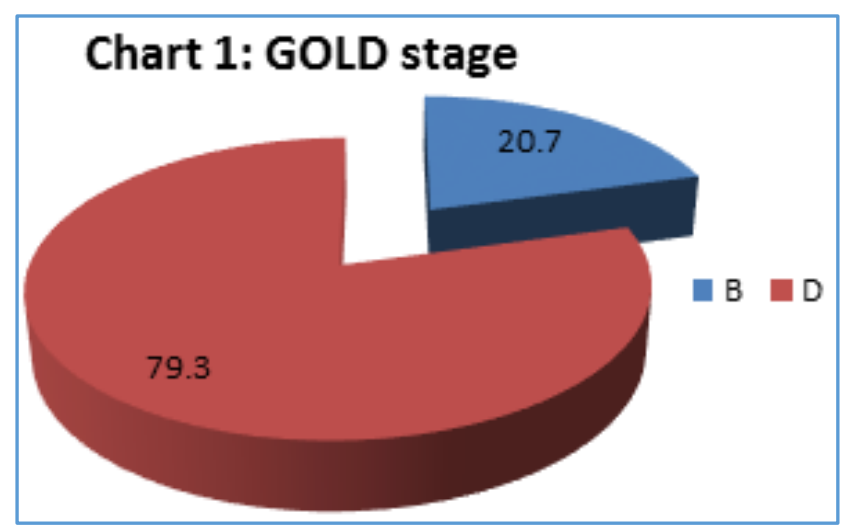

\begin{tabular}{|c|c|c|}
\hline Score & Number & Percentage \\
\hline \multicolumn{3}{|c|}{ BODE index } \\
\hline$<5$ & 53 & $17.7 \%$ \\
\hline$>5$ & 247 & $82.3 \%$ \\
\hline Total & $\mathbf{3 0 0}$ & $\mathbf{1 0 0 \%}$ \\
\hline \multicolumn{3}{|c|}{ DOSE index } \\
\hline$<4$ & 72 & $24 \%$ \\
\hline$>4$ & 228 & $76 \%$ \\
\hline Total & $\mathbf{3 0 0}$ & $\mathbf{1 0 0} \%$ \\
\hline
\end{tabular}




\begin{tabular}{|c|c|c|}
\hline \multicolumn{3}{|c|}{ ADO index } \\
\hline$<5$ & 72 & $24 \%$ \\
\hline$>5$ & 228 & $76 \%$ \\
\hline Total & $\mathbf{3 0 0}$ & $\mathbf{1 0 0 \%}$ \\
\hline \multicolumn{2}{|c|}{ Table 2. Multidimensional Systems } \\
\hline
\end{tabular}

\begin{tabular}{|c|c|c|c|c|c|}
\hline Variables & $\mathbf{N}$ & Min & Maxi & Mean & $\begin{array}{c}\text { Std. } \\
\text { Deviation }\end{array}$ \\
\hline Age (yrs.) & 300 & 50 & 89 & 65.83 & 7.57 \\
\hline $\mathrm{BMI}$ & 300 & 19 & 28 & 21.90 & 1.45 \\
\hline $\mathrm{SS}$ & 300 & 0 & 2500 & 704.17 & 405.6 \\
\hline $\mathrm{SPO}_{2}$ & 300 & 78 & 99 & 93.67 & 4.80 \\
\hline $\mathrm{SPO}_{2} @ 1 \mathrm{yr}$. & 264 & 81 & 99 & 91.61 & 3.47 \\
\hline $6 \mathrm{MWD}(\mathrm{M})$ & 300 & 0 & 510 & 144.45 & 140.2 \\
\hline 6MWD 1yr. & 264 & 0 & 460 & 99.1 & 109.6 \\
\hline $\mathrm{FEV}_{1 \%}$ & 300 & 17 & 78 & 40.31 & 14.95 \\
\hline $\mathrm{FEV}_{1} 1 \mathrm{yr}$. & 264 & 20 & 65 & 41.36 & 14.40 \\
\hline \multicolumn{7}{|c|}{ Table 3. Descriptive Statistics } \\
\hline
\end{tabular}

FEV1-Forced expiratory volume in 1 second; BMI - Body Mass Index; SS - Smoking Score;

SP02 -0xygen saturation; 6 MWD - Six-minute walk distance in metres.

\begin{tabular}{|c|c|c|c|}
\hline \multirow{2}{*}{ GOLD } & \multicolumn{2}{|c|}{ Exacerbation } & \multirow{2}{*}{ Total } \\
\cline { 2 - 3 } & $>=\mathbf{2} /$ yrs. & $\mathbf{0 - 1} / \mathbf{y r}$. & \multirow{2}{*}{62} \\
\hline \multirow{2}{*}{$\mathrm{B}$} & $\begin{array}{c}22 \\
(35.5 \%)\end{array}$ & $\begin{array}{c}40 \\
(64.5 \%)\end{array}$ & 62 \\
\hline \multirow{2}{*}{$\mathrm{D}$} & $\begin{array}{c}203 \\
(85.3 \%)\end{array}$ & $\begin{array}{c}35 \\
(14.7 \%)\end{array}$ & 238 \\
\hline \multirow{2}{*}{ Total } & $\begin{array}{c}\mathbf{2 2 5} \\
(\mathbf{7 5 \%})\end{array}$ & $\begin{array}{c}\mathbf{7 5} \\
(\mathbf{2 5 \% )}\end{array}$ & $\begin{array}{c}\mathbf{3 0 0} \\
(\mathbf{1 0 0} \%)\end{array}$ \\
\hline \multicolumn{4}{|c|}{ Table 4. Exacerbations in GOLD stages } \\
\hline
\end{tabular}

\begin{tabular}{|c|c|c|c|c|c|c|}
\hline \multirow{2}{*}{$\begin{array}{c}\text { Exacerbation } \\
\text { @1year }\end{array}$} & \multicolumn{2}{|c|}{ DOSE } & \multicolumn{2}{|c|}{ ADO } & \multicolumn{2}{|c|}{ BODE } \\
\hline & $<4$ & $>4$ & $<5$ & $>5$ & $<5$ & $>5$ \\
\hline $0-1$ & 45 & 26 & 32 & 31 & 32 & 30 \\
\hline$>\_2$ & 27 & 166 & 30 & 171 & 14 & 188 \\
\hline Total & 72 & 192 & 62 & 202 & 46 & 218 \\
\hline $\begin{array}{l}\text { Pearson's chi } \\
\text { square value }\end{array}$ & \multicolumn{2}{|c|}{71.053} & \multicolumn{2}{|c|}{38.986} & \multicolumn{2}{|c|}{68.940} \\
\hline Df & \multicolumn{2}{|c|}{1} & \multicolumn{2}{|c|}{1} & \multicolumn{2}{|c|}{1} \\
\hline P value & \multicolumn{2}{|c|}{$<.001$} & \multicolumn{2}{|c|}{$<.001$} & \multicolumn{2}{|c|}{$<.001$} \\
\hline Risk estimate & \multicolumn{2}{|c|}{$\begin{array}{c}2.316(95 \% \mathrm{CI} \\
1.711-3.134)\end{array}$} & \multicolumn{2}{|c|}{$\begin{array}{c}1.774(95 \% \mathrm{CI} \\
1.381-2.280)\end{array}$} & \multicolumn{2}{|c|}{\begin{tabular}{|c}
$2.803(95 \%$ CI \\
$1.855-4.235)$
\end{tabular}} \\
\hline
\end{tabular}

The characteristics of the patients who were classified as $<2$ or $>2$ exacerbations per year of the study were shown (Table-5). The risk for exacerbations were calculated for GOLD, DOSE, ADO and BODE using Pearson's chi square test and the resultant values were statistically significant with a $p$ $<0.001$ suggesting correlation between the variables and exacerbations. The values obtained by comparing different groups were tested using ROC for assessing their predictive capacity. The AUC values for prediction of exacerbations for the, BODE index, ADO and DOSE index were 0.944 (SE 0.015, $\mathrm{P}<0.001$ ), 0.818 (SE 0.016, $\mathrm{P}<0.001$ ), 0.939 (SE 0.016, $\mathrm{P}<0.001$ ) respectively (Chart 2 ). The curves obtained for BODE, DOSE and ADO were found to be lying closer to coordinates far to the left of the reference line suggesting significant predictive power. All these indices were found to be significant in predicting exacerbations, BODE index had a higher value compared to other indices $(\mathrm{P}<0.001)$. Less than
2 exacerbations in the previous year before the study were $27.3 \%$ and it was only $13 \%$ during the study period (Table 1 ). The mean rate of exacerbation for the entire group during the study period were 2.8 events per patient-year, 225 (75\%) patients reported two or more exacerbations and 25\% experienced at least one exacerbation during the study period. Patients who experienced exacerbations had significantly lower FEV1\% predicted values and in GOLD stage D. All of these multidimensional assessment scores were significantly worse in patients with low 6 MWD results and high mMRC scores, than those who had $<2$ exacerbations (Table 5).

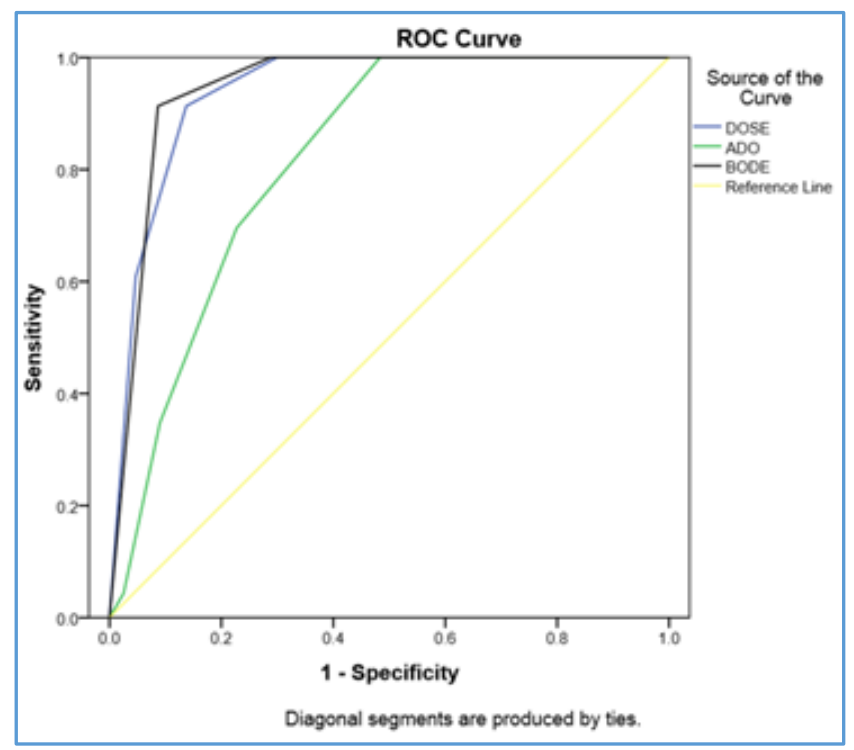

Chart 2. Receiver Operator Curve for Predicting Exacerbations using Multidimensional Systems

\begin{tabular}{|c|r|r|r|}
\hline \multicolumn{4}{|c|}{ Coordinates of the Curve } \\
\hline Test Result Variable(s) & $\begin{array}{c}\text { Positive if } \\
\text { Greater Than } \\
\text { or Equal To }\end{array}$ & Sensitivity & 1 - Specificity \\
\hline DOSE & 6.50 & .913 & .137 \\
\hline ADO & 5.50 & 1.000 & .484 \\
& 6.50 & .696 & .227 \\
\hline BODE & 8.50 & 1.000 & .289 \\
& 9.50 & .913 & .087 \\
\hline
\end{tabular}

\section{DISCUSSION}

In this study, out of 300 patients recruited 287 (95.7\%) were male and only a minority $13(4.3 \%)$ were female. The comorbidities detected were Diabetes mellitus (26\%), Systemic hypertension (28\%) and Pulmonary hypertension (16\%). $86 \%$ of the patients were ex-smokers, $5.3 \%$ current smokers and $8.7 \%$ non-smokers. The number of current smokers was small compared to other studies. $82.7 \%$ had $>2$ exacerbations and $27.3 \%$ had $<2$ exacerbation in the previous year. Most of the patients were in grade $3 \mathrm{mMRC}(61 \%)$. All the patients in our study were GOLD group B or D, might be because the study was conducted in a tertiary care centre. In Group B there were 62 patients (20.7\%) and in group D 238 patients $(79.3 \%)$. The exacerbation rates in the GOLD groups suggest that more than $85 \%$ of patients in the D had more than 2 exacerbations per year whereas $35.5 \%$ in the group B having more than 2 exacerbations. This finding is not unexpected since we had patients with advanced disease. 
Multidimensional assessment tools in COPD (such as BODE index, DOSE index, etc.) have been used in predicting mortality, exacerbation and risk of hospitalisations. ${ }^{[2]}$ Studies have attempted whether these systems can be used to predict outcomes in COPD but did not get a consistent result in different populations. No reliable studies from India have addressed this question. In the absence of such evidence it is prudent not to use such multidimensional systems in Indian population.[10] In this study, multidimensional assessment systems, i.e., the BODE, ADO, and DOSE indices, were tested for their ability to predict outcomes in COPD patients. Analysing data, we found that all these multidimensional systems were good at predicting outcomes in the form of exacerbations in COPD. All these indices were having AUC ROC above the significant level (ADO 0.818; $<<0.001$, BODE 0.944, $\mathrm{p}<0.001$; DOSE 0.939, $\mathrm{p}<0.001$ ). BODE index was the largest of the three indices value under ROC (chart-2). BODE index was evaluated by Faganello et al, for its ability to predict exacerbations. Their conclusion was that it is as effective as GOLD classifications in predicting exacerbations. [11] Marin et al also found BODE index useful as a predictor. They found that BODE was better in predicting severity of exacerbations as well as the number of exacerbations compared to FEV1.[6] Age group of patients in this study was similar to ours, but our population had high exacerbation rate (2.8 versus 1.95). Whereas studies by Takashi Motegi et al and Sundh et al have found that DOSE index was useful as a predictor of exacerbations in COPD.[14,15] Another important finding in our study was the high exacerbation rate compared to the annual exacerbation rates reported in other studies. The reasons for this might be the high COPD severity group participation in our study or whether it is due to the phenotypic variation in ethnic populations needs to be assessed.

\section{CONCLUSION}

This study assessed COPD using three multidimensional assessment tools for their utility in the prediction of exacerbation of COPD based on GOLD 2013 criteria. Our findings indicate that these composite scores can be used to predict COPD exacerbations in Indian patients. The BODE index was better at predicting exacerbations of COPD than the DOSE and ADO indices.

\section{Limitations}

The study was conducted at a tertiary care centre and majority of the patients were in GOLD Group D (79.3\%), which is not suitable for evaluation for exacerbation risk. Small sample size may make it difficult to extrapolate the findings to the general patient population. We had followed up the patients only for one year. So we had to rely on history and past medical records to assess previous exacerbation rates, both of which are prone for incomplete information.

\section{ACKNOWLEDGEMENTS}

We extend our sincere gratitude to Dr. Biju George from the Department of Community Medicine and Dr. Kiran Vishnunarayanan from the Department of Pulmonary Medicine for their creative support.

\section{REFERENCES}

[1] Vestbo J, Hurd SS, Agustí AG, et al. Global strategy for the diagnosis, management, and prevention of chronic obstructive pulmonary disease. AJRCCM 2013;187(4).

[2] Celli BR, Cote CG, Marin JM, et al. The body-mass index, airflow obstruction, dyspnea, and exercise capacity index in chronic obstructive pulmonary disease. N Engl J Med 2004;350(10):1005-12.

[3] Puhan MA, Garcia-Aymerich J, Frey M, et al. Expansion of the prognostic assessment of patients with chronic obstructive pulmonary disease: the updated BODE index and the ADO index. Lancet 2009;374(9691):704-11.

[4] Jones RC, Donaldson GC, Chavannes $\mathrm{NH}$, et al. Derivation and validation of a composite index of severity in chronic obstructive pulmonary disease: the DOSE index. Am J Respir Crit Care Med 2009;180(12):1189-95.

[5] Grippi MA, Elias JA, Fishman JA, et al. Fishman's pulmonary diseases and disorders. $5^{\text {th }}$ edn. McGrawHill Medical 2015:1453-4.

[6] Marin JM, Carrizo SJ, Casanova C, et al. Prediction of risk of COPD exacerbations by the BODE index. Respir Med 2009;103(3):373-8.

[7] Eisner MD, Blanc PD, Omachi TA, et al. Socioeconomic status, race and COPD health outcomes. J Epidemiol Community Health 2011;65(1):26-34.

[8] Langsetmo L, Platt RW, Ernst P, et al. Underreporting exacerbation of chronic obstructive pulmonary disease in a longitudinal cohort. Am J Respir Crit Care Med 2008;177(4):396-401.

[9] Chavannes NH, Jones RC, Postma DS, et al. Using COPD multidimensional indices in routine clinical practice: DOSE meets all criteria. Prim Care Respir J 2012;21(3):245-6.

[10] Gupta D, Agarwal R, Aggarwal AN, et al. Guidelines for diagnosis and management of chronic obstructive pulmonary disease: joint recommendations of Indian chest society and national college of chest physicians (India). Indian J Chest Dis Allied Sci 2014;56:5-54.

[11] Faganello MM, Tanni SE, Sanchez FF, et al. BODE index and GOLD staging as predictors of 1-year exacerbation risk in chronic obstructive pulmonary disease. Am J Med Sci 2010;339(1):10-4. 